\title{
A hot water extract of turmeric (Curcuma longa) suppresses acute ethanol-induced liver injury in mice by inhibiting hepatic oxidative stress and inflammatory cytokine production
}

\author{
Ryusei Uchio ${ }^{1}$, Yohei Higashi ${ }^{1}$, Yusuke Kohama ${ }^{2}$, Kengo Kawasaki ${ }^{1}$, Takashi Hirao ${ }^{2}$, \\ Koutarou Muroyama ${ }^{1}$ and Shinji Murosaki ${ }^{1}$ \\ ${ }^{1}$ Research \& Development Institute, House Wellness Foods Corporation, 3-20 Imoji, Itami 664-0011, Japan \\ ${ }^{2}$ Central Research \& Development Institute, House Foods Group Inc., 1-4 Takanodai, Yotsukaido 284-0033, Japan
}

(Received 11 April 2016 - Final revision received 20 November 2016 - Accepted 28 November 2016)

Journal of Nutritional Science (2017), vol. 6, e3, page 1 of 9

doi:10.1017/jns. 2016.43

Abstract

Turmeric (Curcuma longa) is a widely used spice that has various biological effects, and aqueous extracts of turmeric exhibit potent antioxidant activity and anti-inflammatory activity. Bisacurone, a component of turmeric extract, is known to have similar effects. Oxidative stress and inflammatory cytokines play an important role in ethanol-induced liver injury. This study was performed to evaluate the influence of a hot water extract of C. longa (WEC) or bisacurone on acute ethanol-induced liver injury. C57BL/ 6 mice were orally administered WEC ( $20 \mathrm{mg} / \mathrm{kg}$ body weight; BW) or bisacurone (60 $\mu \mathrm{g} / \mathrm{kg}$ BW) at $30 \mathrm{~min}$ before a single dose of ethanol was given by oral administration $(3.0 \mathrm{~g} / \mathrm{kg} \mathrm{BW})$. Plasma levels of aspartate aminotransferase and alanine aminotransferase were markedly increased in ethanol-treated mice, while the increase of these enzymes was significantly suppressed by prior administration of WEC. The increase of alanine aminotransferase was also significantly suppressed by pretreatment with bisacurone. Compared with control mice, animals given WEC had higher hepatic tissue levels of superoxide dismutase and glutathione, as well as lower hepatic tissue levels of thiobarbituric acid-reactive substances, TNF- $\alpha$ protein and IL-6 mRNA. These results suggest that oral administration of WEC may have a protective effect against ethanol-induced liver injury by suppressing hepatic oxidation and inflammation, at least partly through the effects of bisacurone.

Key words: Turmeric (Curcuma longa): Bisacurone: Ethanol-induced liver injury: Oxidative stress: Inflammatory cytokines

Alcohol is a popular beverage in most parts of the world and it has long been identified as a major risk factor for liver disease $^{(1)}$, with excessive alcohol consumption causing impairment of both physical and mental health. The liver is the main site of ethanol metabolism and is also the principal target organ for ethanol-induced damage. Excessive ethanol consumption can trigger the progression of alcoholic liver disease, which covers a wide spectrum from steatosis to steatohepatitis, fibrosis and/or cirrhosis in severe cases ${ }^{(2,3)}$.

Oxidative stress is well known to play a key role in the pathogenesis of acute ethanol-induced liver injury ${ }^{(3,4)}$. Ethanol consumption induces excessive production of reactive oxygen species (ROS), which decrease hepatic tissue levels of superoxide dismutase (SOD) and glutathione (GSH), leading to overload of the antioxidant system and failure to efficiently remove ROS. As a result, hepatocyte necrosis and/or apoptosis are induced by oxidation of lipids, proteins and $\mathrm{DNA}^{(5-7)}$. Therefore, maintenance of hepatic antioxidant capacity is expected to alleviate ethanol-induced liver injury, and antioxidant therapy has been reported to prevent ethanol-induced liver damage ${ }^{(7-9)}$.

Clinical and animal studies have revealed that inflammatory cytokines such as TNF- $\alpha$ and IL- 6 are key mediators of

Abbreviations: ALT, alanine aminotransferase; AST, aspartate aminotransferase; BW, body weight; GSH, glutathione; GSSG, oxidised glutathione; $\mathrm{O}_{2}^{--}$, superoxide anion radical; ROS, reactive oxygen species; SOD, superoxide dismutase; TBARS, thiobarbituric acid-reactive substances; WEC, hot water extract of Curcuma longa.

* Corresponding author: R. Uchio, fax +81 72778 0892, email Uchio_Ryusei@house-wf.co.jp 
ethanol-induced liver injury ${ }^{(10,11)}$. TNF- $\alpha$ was reported to induce hepatocyte apoptosis and liver injury in vivo via a cathepsin B-mediated pathway ${ }^{(12)}$. It was also reported that reduction of TNF- $\alpha$ and IL- 6 levels by suppression of oxidative activity can alleviate ethanol-induced liver inflammation ${ }^{(13)}$.

Turmeric (Curcuma longa) is a widely used spice that possesses various biological activities ${ }^{(14,15)}$. For example, aqueous extracts of turmeric have been reported to exhibit antioxidant activity ${ }^{(16)}$ and anti-inflammatory activity ${ }^{(17)}$, as well as promoting corneal wound healing ${ }^{(18)}$, an antidepressant effect ${ }^{(19)}$, an anticancer effect ${ }^{(20)}$ and regulating cytochrome P450 (CYP) activity $^{(21)}$. We recently reported that a hot water extract of $C$. longa (WEC) modulates the adhesive properties of endothelial cells by suppressing TNF- $\alpha$-induced expression of cell adhesion molecules via inhibition of the NF- $\mathrm{KB}$ signalling pathway ${ }^{(22)}$. These effects of WEC are at least partly attributable to bisacurone, a component of turmeric that has both antioxidant and anti-inflammatory activities ${ }^{(17,23)}$. However, the influence of WEC or bisacurone on ethanol-induced liver injury has not yet been investigated.

Accordingly, the present study was performed to determine the effects of oral administration of WEC or bisacurone on ethanol-induced liver injury in mice by examining plasma markers of liver damage. We also assessed the effects of WEC on hepatic oxidation and inflammation in ethanol-treated mice.

\section{Materials and methods}

\section{Preparation of a hot water extract of Curcuma longa}

WEC was prepared according to the method described previously $^{(22)}$. In brief, rhizomes of turmeric (Curcuma longa Linn.) were extracted with hot water at $95^{\circ} \mathrm{C}$, after which the supernatant fraction was concentrated under reduced pressure and WEC powder was obtained by spray drying. This powder was stored at $4^{\circ} \mathrm{C}$ until use. WEC powder had a bisacurone content of $0.302 \%(\mathrm{w} / \mathrm{w})$ and a curcumin content of $0.125 \%(w / w)$.

\section{Preparation of bisacurone}

WEC was incubated with methanol-water (90:10) and the extract was freeze-dried. Then the freeze-dried powder was dissolved in acetonitrile-water (30:70) and subjected to preparatory reverse-phase HPLC (YMC ODS-A-HG column (YMC Co.), mobile phase: acetonitrile-water (35:65)). The fraction containing bisacurone was concentrated and dissolved in ethyl acetate-hexane (80:20), after which the resulting solution was subjected to silica gel open column chromatography (YMC GEL SIL-HG; YMC Co.). Next, the eluate was concentrated and dissolved in ethyl acetate-chloroform (64:36), following which the resulting solution was applied to a preparatory normal-phase MPLC system (ULTRA PACK SI-40B column, mobile phase: ethyl acetate-chloroform (64:36 to 38:62)). After the fraction containing bisacurone was concentrated, it was dissolved in acetonitrile-water (30:70) and the resulting solution was applied to a preparatory reverse-phase HPLC system (ULTRON VX-ODS column, mobile phase: acetonitrile-water
(30:70)). Subsequently, the fraction containing bisacurone was concentrated and extracted with chloroform-water (35:65), after which the chloroform layer was dried and concentrated to obtain bisacurone. The bisacurone content of this final material was $83.6 \%$, as determined by quantitative $\mathrm{NMR}^{(24)}$.

\section{Animals}

Specific-pathogen-free male C57BL/6N CrlCrlj mice were purchased from Charles River Japan and were acclimatised for $7 \mathrm{~d}$ on the basal diet before experiments were performed. The basal diet was based on the American Institute of Nutrition (AIN)-93G $\operatorname{diet}^{(25)} \cdot \alpha$-Maize starch, casein, soyabean oil, cellulose powder, AIN-93G mineral mixture, and AIN-93 vitamin mixture were purchased from Oriental Yeast Co. Maize starch and sucrose were obtained from Matsutani Chemical Industry and Mitsui Sugar Co., Ltd., respectively. Choline bitartrate, L-cystine and tert-butylhydroquinone (TBHQ) were purchased from Wako Pure Chemicals. Throughout the experiments, mice were housed individually in cages and maintained under specific-pathogen-free conditions in a controlled environment (room temperature: $23 \pm$ $1^{\circ} \mathrm{C}$, relative humidity: $55 \pm 5 \%$, and $12 \mathrm{~h}$ light $-12 \mathrm{~h}$ dark cycle). All experiments were performed with 9-week-old male C57BL/6N mice (19-22 g) in accordance with the guidelines of the Animal Care and Use Committee of the House Wellness Foods Corporation.

\section{Experimental design}

C57BL/6N mice were allocated to a control group and a WEC (20 mg/kg body weight (BW)) group or to a control group and a bisacurone $(60 \mu \mathrm{g} / \mathrm{kg} \mathrm{BW})$ group so that the BW of each group was balanced. The group size for these experiments was determined as follows. Our preliminary study revealed that the mean plasma alanine aminotransferase (ALT) level was approximately 11 (SD 2) IU/l at $6 \mathrm{~h}$ after administration of a single dose of ethanol $(3.0 \mathrm{~g} / \mathrm{kg} \mathrm{BW})$ to $\mathrm{C} 57 \mathrm{BL} / 6 \mathrm{~N}$ mice. In addition, the antioxidant $N$-acetylcysteine was reported to inhibit elevation of the plasma ALT level (by about $40 \% v$. the control group) at $6 \mathrm{~h}$ after administration of ethanol to mice ${ }^{(9)}$. Based on an expected mean plasma ALT level of 11 (SD 2) IU/l at $6 \mathrm{~h}$ after ethanol administration and a targeted $40 \%$ reduction of plasma ALT by WEC, a group size of six mice was estimated to give the study a statistical power of $80 \%$ with a type I error of $5 \%$. Mice were orally administered WEC at the dose of $20 \mathrm{mg} / \mathrm{kg}$ BW in the WEC group and received bisacurone at the dose of $60 \mu \mathrm{g} / \mathrm{kg} \mathrm{BW}$ in the bisacurone group, while the respective control groups were given the same dose of the vehicle $(0.5$ $\%(\mathrm{w} / \mathrm{v})$ methylcellulose in water (Wako Pure Chemical Industries)). Ethanol was orally administered to the mice $(3.0 \mathrm{~g} / \mathrm{kg} \mathrm{BW}$ and $200 \mu \mathrm{l} / 20 \mathrm{~g} \mathrm{BW}$ ) as a $15 \%$ (w/v) solution in water at $30 \mathrm{~min}$ after administration of WEC, bisacurone or the vehicle. Plasma aspartate aminotransferase (AST) and ALT levels were measured immediately before and 1,2, 4 and $6 \mathrm{~h}$ after ethanol administration in all experiments. Hepatic tissue levels of SOD, GSH, the GSH:oxidised-GSH (GSSG) ratio, 
thiobarbituric acid-reactive substances (TBARS), TNF- $\alpha$ protein and mRNA, and IL- 6 mRNA were also measured at 1, 2 , 4 and $6 \mathrm{~h}$ after ethanol administration. These parameters were measured in untreated control mice that did not receive WEC or ethanol ( $n$ 12), as well as in the ethanol-treated control group and the ethanol-treated WEC group (both $n$ 6). Blood samples were collected from the retro-orbital sinus into heparinised calibrated pipettes (Drummond Scientific Company). Mice were anaesthetised with diethyl ether immediately before being killed by exsanguination, after which their livers were harvested and washed with saline to minimise contamination by blood.

\section{Measurement of plasma aspartate aminotransferase and} alanine aminotransferase

Blood samples were centrifuged $\left(12000 \mathrm{~g}\right.$ for $10 \mathrm{~min}$ at $\left.4^{\circ} \mathrm{C}\right)$ immediately after collection to obtain plasma. Then AST and ALT were measured by the pyruvate oxidase- $N$-ethyl- $N-(2-$ hydroxy-3-sulfopro-pyl)-m-toluidine (POP-TOOS) method with commercial kits (Transaminase CII-test Wako; Wako Pure Chemical) according to the manufacturer's instructions ${ }^{(26,27)}$.

\section{Hepatic histological analysis}

Liver tissue specimens were fixed in $10 \%(\mathrm{v} / \mathrm{v})$ neutral buffered formalin (Wako Pure Chemical), dehydrated in an ethanol series, cleared in xylene and embedded in paraffin. The paraffin blocks were cut into sections approximately $5 \mu \mathrm{m}$ thick, which were defatted with xylene and stained with haematoxylin and eosin $(\mathrm{H} \& \mathrm{E})$ (Merck) ${ }^{(28,29)}$. Sections were viewed under an inverted microscope (Olympus IX-73; Olympus) (original magnification $\times 160$ ).

\section{Measurement of hepatic superoxide dismutase activity}

Liver tissue $(30 \mathrm{mg})$ was homogenised in eight volumes of sucrose buffer ( $0.25 \mathrm{M}$-sucrose, $10 \mathrm{~mm}$-Tris(hydroxymethyl) aminomethane (Tris), 1 mm-EDTA, pH 7.40) using a disposable homogeniser (BioMasher II; Nippi Inc.). The homogenate was sonicated once with a Sonifire SLPe 40 (Branson) for $3 \mathrm{~s}$ at $20 \%$ amplitude on ice and then centrifuged $\left(10000 \mathrm{~g}\right.$ for $60 \mathrm{~min}$ at $4^{\circ} \mathrm{C}$ ), after which the supernatant was stored at $-80^{\circ} \mathrm{C}$ until use. SOD activity was measured by the water-soluble tetrazolium salt (WST) method using a SOD assay kit-WST (Dojindo Inc.), according to the manufacturer's instructions ${ }^{(30,31)}$. One unit $(\mathrm{U})$ of SOD activity was defined as causing $50 \%$ inhibition of the assay reaction and hepatic SOD activity was normalised per g liver tissue (wet weight).

Measurement of the hepatic glutathione level and glutathione:oxidised glutathione ratio

Liver tissue $(100 \mathrm{mg})$ was added to 10 volumes of $5 \%(\mathrm{w} / \mathrm{v})$ 5-sulfosalicyclic acid (SSA) solution and was homogenised with a disposable homogeniser. The homogenate was centrifuged at $8000 \mathrm{~g}$ for $10 \mathrm{~min}$ at $4^{\circ} \mathrm{C}$, after which the supernatant was diluted 10 -fold with deionised water and stored at $-80^{\circ} \mathrm{C}$ until use. Total GSH and GSSG levels were determined by the enzymic cycling method with 5,5-dithio-bis(2-nitrobenzoic acid) (DTNB) using a GSSG/GSH Quantification Kit (Dojindo Molecular Technologies Inc.), according to the manufacturer's instructions ${ }^{(32,33)}$. Then the GSH level was calculated from the difference between total GSH and GSSG, and the GSH:GSSG ratio was also calculated. Both the hepatic GSH level and GSH:GSSG ratio were normalised per $\mathrm{g}$ liver tissue (wet weight).

\section{Measurement of hepatic lipid peroxides}

The hepatic tissue level of TBARS was measured as a marker of lipid peroxidation. Liver tissue $(20 \mathrm{mg})$ was added to 10 volumes of radioimmunoprecipitation (RIPA) buffer (250 mm-Tris-HCl, $\mathrm{pH}$ 7·6, 750 mm-sodium chloride, $5 \%$ Tergitol (NP-40), 2.5\% sodium deoxycholate, $0.5 \%$ SDS; Cayman Chemical) supplemented with protease inhibitor cocktail (Sigma-Aldrich) and was homogenised with a disposable homogeniser. The homogenate was sonicated twice with a Sonifire SLPe 40 for $3 \mathrm{~s}$ at $20 \%$ amplitude on ice and centrifuged $\left(1600 \mathrm{~g}\right.$ for $10 \mathrm{~min}$ at $4^{\circ} \mathrm{C}$ ), after which the supernatant fraction was stored at $-80^{\circ} \mathrm{C}$ until use. TBARS were determined by fluorometric measurement of malondialdehyde and thiobarbituric acid (MDA-TBA) adducts using a TBARS assay kit (Cayman Chemical) according to the manufacturer's protocol ${ }^{(34,35)}$, and the hepatic TBARS level was normalised per $g$ liver tissue (wet weight).

\section{Measurement of hepatic TNF- $\alpha$ protein}

Liver tissue $(200 \mathrm{mg})$ was added to 2.5 volumes of lysis buffer (CelLytic ${ }^{\text {TM MT}}$ M Sigma-Aldrich) supplemented with a protease inhibitor cocktail (Sigma-Aldrich) and was homogenised by using a disposable homogeniser. The homogenate was sonicated once with a Sonifire SLPe 40 for $3 \mathrm{~s}$ at $20 \%$ amplitude on ice and centrifuged $\left(16000 \mathrm{~g}\right.$ for $10 \mathrm{~min}$ at $\left.4^{\circ} \mathrm{C}\right)$, after which the supernatant fraction was stored at $-80^{\circ} \mathrm{C}$ until use. TNF- $\alpha$ protein was determined by a sandwich ELISA using the Quantikine ${ }^{\circledR}$ mouse TNF- $\alpha$ ELISA kit (R\&D Systems) according to the manufacturer's instructions ${ }^{(36-38)}$, and the hepatic TNF- $\alpha$ level was normalised per $g$ liver tissue (wet weight).

\section{Measurement of hepatic TNF- $\alpha$ and IL-6 mRNA expression}

After RNAlater ${ }^{\circledR}$ (Ambion Inc.) solution $(300 \mu \mathrm{l})$ was added to liver tissue $(30 \mathrm{mg})$ to prevent degradation of mRNA, the tissue samples were stored at $-80^{\circ} \mathrm{C}$ until use. Total RNA was prepared by using the RNeasy ${ }^{\circledR}$ Mini Kit (Qiagen), and DNA was removed by on-column DNase digestion with an RNase-free DNase Set (Qiagen) according to the manufacturer's protocol. Then expression of TNF- $\alpha$, IL- 6 and $\beta$-actin mRNA was measured by real-time $\mathrm{PCR}^{(39)}$. In brief, synthesis of cDNA and PCR were performed using the Thermal Cycler Dice ${ }^{\circledR}$ Real Time System TP800 (Takara) and One Step SYBR $^{\circledR}$ PrimeScript ${ }^{\mathrm{TM}}$ RT-PCR Kit II 
(Takara) according to the manufacturer's instructions. The specific primer for TNF- $\alpha$ was obtained from Life Technologies, Inc., while the primers for IL-6 and $\beta$-actin were obtained from Takara. Primer sequences were as follows: TNF- $\alpha$ (forward primer 5'-CCTGTAGCCCACGTCGT AG-3', reverse primer; 5'-GGGAGTAGACAAGGTACAA CCC-3'), IL-6 (forward primer 5'-CCACTTCACAAG TCGGGAGGCTTA-3', reverse primer; 5'-CCAGTTTGG TAGCATCCATCATT'TC- ${ }^{\prime}$ ) and $\beta$-actin (forward primer 5'-GGCTGTATTCCCCTCCATCG-3', reverse primer; 5'-C CAGT'TGGTAACAATGCCATGT-3'). Data were analysed by the $2^{-\Delta \Delta C T}$ method $^{(40)}$ using the second derivative curve of amplification plots (Thermal Cycler Dice Real Time System software version 4.00B; Takara). Expression of TNF- $\alpha$ and IL- 6 mRNA was normalised for $\beta$-actin mRNA expression.

\section{Statistical analysis}

Differences between two groups were assessed with Student's unpaired $t$ test. Data were also analysed by one-way ANOVA, followed by the Tukey-Kramer test, for comparison between the untreated control group and the ethanol-treated control group. All analyses were performed using Statcel 3 software (OMS Publishing). Results are shown as mean values and standard deviations. $P<0.05$ was considered to indicate statistical significance.

\section{Results}

Effect of hot water extract of Curcuma longa on plasma aspartate aminotransferase and alanine aminotransferase levels after acute ethanol administration

Because aqueous extracts of turmeric have been reported to protect the liver from injury by carbon tetrachloride ${ }^{(41)}$, we evaluated the effect of WEC on ethanol-induced liver injury. Mice were orally administered the vehicle or WEC (20 mg/ kg), and a single dose of ethanol $(3.0 \mathrm{~g} / \mathrm{kg})$ was given after $30 \mathrm{~min}$.
In the control group, plasma AST and ALT levels were markedly increased at 1, 2, 4 and $6 \mathrm{~h}$ after ethanol administration. In the WEC group, the plasma AST level was significantly lower at 1, 2, 4 and $6 \mathrm{~h}$ after ethanol administration compared with that in the control group (Fig. 1(A)). Plasma ALT was also significantly lower at 4 and $6 \mathrm{~h}$ in the WEC group compared with the control group (Fig. 1(B)).

\section{Effect of bisacurone on plasma aspartate aminotransferase and alanine aminotransferase levels after acute ethanol administration}

Bisacurone is a component of turmeric extract with both antioxidant and anti-inflammatory activities ${ }^{(17,23)}$. Therefore, we also evaluated the effect of pretreatment with bisacurone on ethanol-induced liver injury when it was given to mice at a dose corresponding to the bisacurone content in WEC. Mice were orally administered the vehicle or bisacurone $(60 \mu \mathrm{g} / \mathrm{kg})$, and a single dose of ethanol $(3.0 \mathrm{~g} / \mathrm{kg})$ was given after $30 \mathrm{~min}$. In the control group, plasma AST and ALT levels showed a marked increase at 1, 2, 4 and $6 \mathrm{~h}$ after ethanol administration. While the plasma AST level showed no significant difference between the control group and the bisacurone group (Fig. 2 (A)), plasma ALT was significantly lower at $4 \mathrm{~h}$ after ethanol administration in the bisacurone group compared with the control group (Fig. 2(B)).

\section{Effect of hot water extract of Curcuma longa on hepatic histological changes after acute ethanol administration}

Ingestion of ethanol causes acute histological changes of the liver such as microvesicular steatosis ${ }^{(9,37)}$. Accordingly, we examined hepatic histology in mice before and $6 \mathrm{~h}$ after administration of ethanol $(3.0 \mathrm{~g} / \mathrm{kg})$ with or without WEC pretreatment. In contrast to normal mice (Fig. 3(A)), lipid droplets (microvesicular steatosis) were observed in the control group after ethanol administration (Fig. 3(B)). The changes were milder in the WEC group, with small lipid droplets being observed after ethanol administration (Fig. 3(C)).
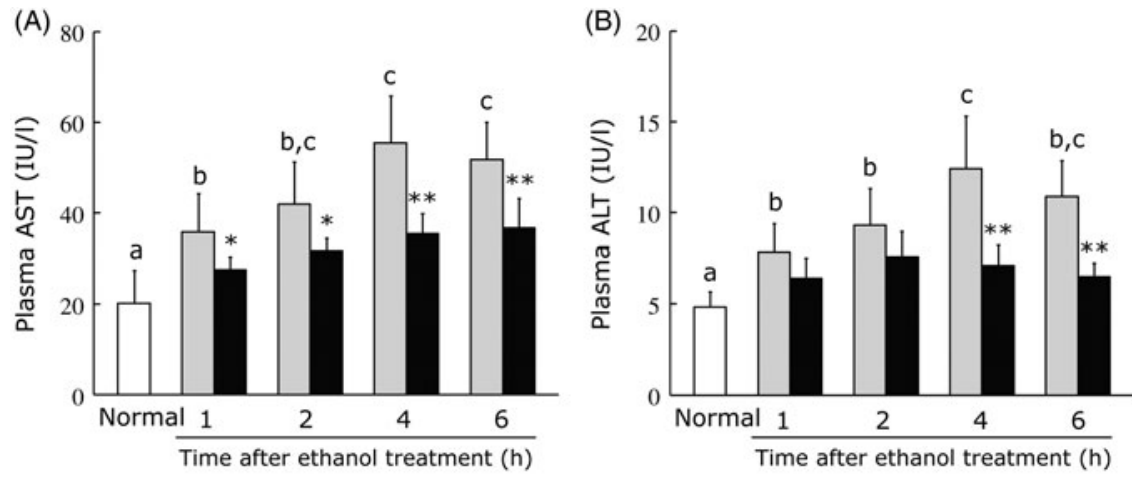

Fig. 1. Effects of oral administration of hot water extract of Curcuma longa (WEC) on plasma liver enzymes after a single dose of ethanol (3.0 g/kg body weight) in mice. Mice were given vehicle ( $)$ or WEC $(\square)$ prior to ethanol administration. Plasma aspartate aminotransferase (AST) (A) and alanine aminotransferase (ALT) (B) levels were measured immediately before ( $\square$ ) and after the ethanol administration. Values are means for $n 6$ (control and WEC groups) or $n 12$ (normal group), with standard deviations represented by vertical bars. ${ }^{a, b, c}$ For bars accompanied by letters, mean values with unlike letters were significantly different $(P<0.05$; one-way ANOVA, post hoc Tukey-Kramer test). Mean value was significantly different from that of the control group: * $P<0.05$, ${ }^{\star *} P<0.01$ (unpaired Student's $t$ test). IU, international units. 

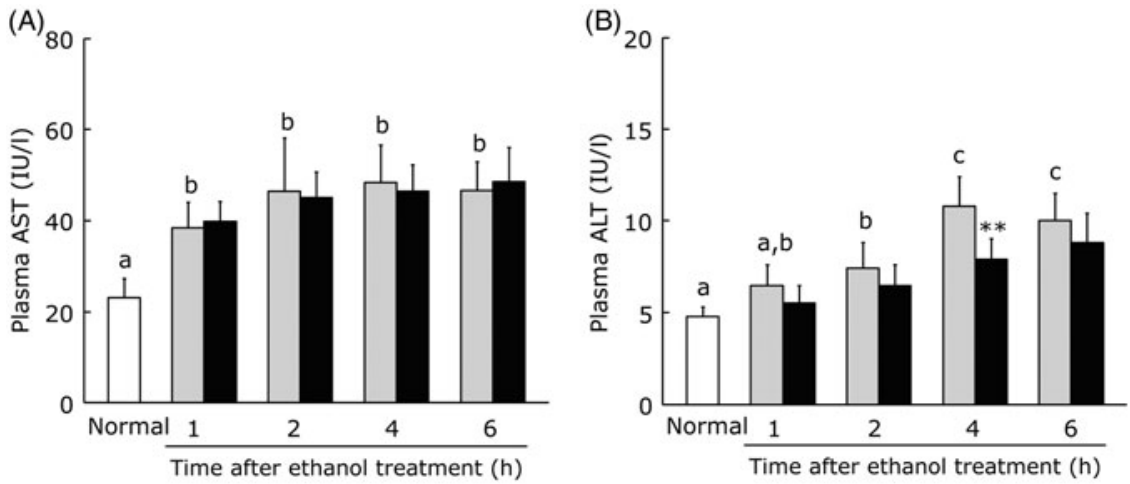

Fig. 2. Effects of oral administration of bisacurone on plasma liver enzymes after a single dose of ethanol ( $3.0 \mathrm{~g} / \mathrm{kg}$ body weight) in mice. Mice were given vehicle (or bisacurone ( $\square$ ) prior to ethanol administration. Plasma aspartate aminotransferase (AST) (A) and alanine aminotransferase (ALT) (B) levels were measured immediately before $(\square)$ and after the ethanol administration. Values are means for for $n 6$ (control and bisacurone groups) or $n 12$ (normal group), with standard deviations represented by vertical bars. ${ }^{\text {a,b,c }}$ For bars accompanied by letters, mean values with unlike letters were significantly different $(P<0.05$; one-way ANOVA, post-hoc Tukey-Kramer test). ${ }^{\star *}$ Mean value was significantly different from that of the control group $(P<0.01$; unpaired Student's $t$ test). IU, international units.
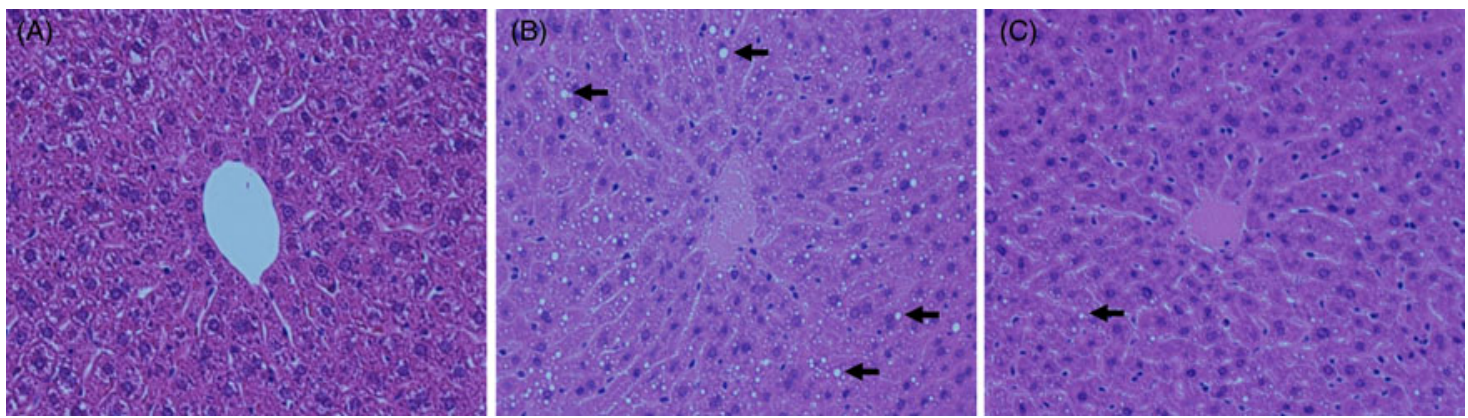

Fig. 3. Effect of hot water extract of Curcuma longa (WEC) on hepatic histological changes after a single dose of ethanol ( $3.0 \mathrm{~g} / \mathrm{kg}$ body weight) in mice. Mice were administered WEC or the vehicle prior to ethanol. Liver histology was examined before and $6 \mathrm{~h}$ after ethanol administration. (A) Normal; (B) control group; (C) WEC group. $\rightarrow$, Lipid droplets. Haematoxylin and eosin stain; original magnification $\times 160$.

\section{Effect of hot water extract of Curcuma longa on hepatic superoxide dismutase, glutathione, glutathione:oxidised glutathione ratio and thiobarbituric acid-reactive substances after acute ethanol administration}

Acute ethanol intake leads to elevation of hepatic lipid peroxidation markers such as TBARS due to consumption of antioxidants such as GSH and depression of SOD activity $^{(42)}$. We measured the hepatic tissue SOD activity, GSH level, GSH:GSSG ratio and TBARS level in mice administered ethanol $(3.0 \mathrm{~g} / \mathrm{kg})$ at $30 \mathrm{~min}$ after receiving WEC or the vehicle. In the control group, hepatic SOD activity showed a significant decrease at 1,2, 4 and $6 \mathrm{~h}$ after ethanol administration, while it was significantly higher at 1 and $2 \mathrm{~h}$ in the WEC group compared with the control group (Fig. 4(A)). In addition, the hepatic GSH level and GSH: GSSG ratio were both significantly decreased at 1,2, 4 and $6 \mathrm{~h}$ after ethanol administration in the control group, while these parameters were significantly higher at $6 \mathrm{~h}$ in the WEC group compared with the control group (Fig. 4 (B) and (C)). Furthermore, the hepatic TBARS level showed a significant increase at 1, 2, 4 and $6 \mathrm{~h}$ after ethanol administration in the control group, whereas it was significantly lower at 4 and $6 \mathrm{~h}$ in the WEC group compared with the control group (Fig. 4(D)).
Effect of hot water extract of Curcuma longa on hepatic TNF- $\alpha$ protein production and expression of TNF- $\alpha$ and IL-6 MRNA after acute ethanol administration

Acute ethanol administration was reported to increase hepatic levels of TNF- $\alpha$ protein, IL- 6 protein and IL- 6 mRNA ${ }^{(37,43)}$. Accordingly, we measured the hepatic TNF- $\alpha$ protein level and TNF- $\alpha$ and IL- 6 mRNA expression in mice given ethanol $(3.0 \mathrm{~g} / \mathrm{kg})$ at $30 \mathrm{~min}$ after administration of WEC or the vehicle. A significant increase of the hepatic TNF- $\alpha$ protein level was found in the control group at 1, 2, 4 and $6 \mathrm{~h}$ after ethanol administration, while TNF- $\alpha$ protein was significantly lower at 1 and $2 \mathrm{~h}$ in the WEC group compared with the control group (Fig. 5(A)). Hepatic TNF- $\alpha$ mRNA and IL-6 mRNA expression did not increase until $4 \mathrm{~h}$ after ethanol administration in the control group (data not shown), but a significant increase was detected at $6 \mathrm{~h}$. TNF- $\alpha$ mRNA expression was lower in the WEC group than the control group at $6 \mathrm{~h}$ after ethanol administration $(P=0.077)$, and hepatic IL-6 mRNA expression was significantly lower in the WEC group at $6 \mathrm{~h}$ (Fig. 5(B) and (C)).

\section{Discussion}

In the present study, WEC significantly prevented acute ethanol-induced liver injury, which was detected by elevation 
(A)

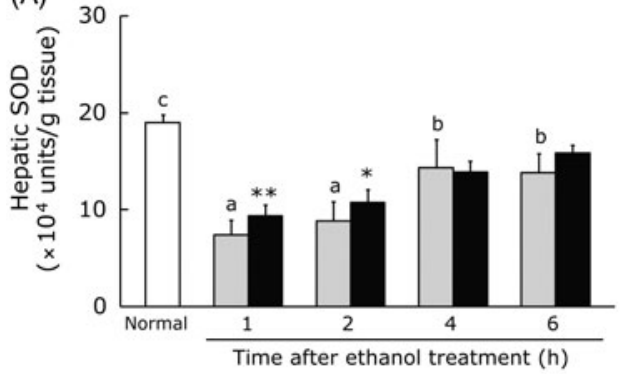

(C)

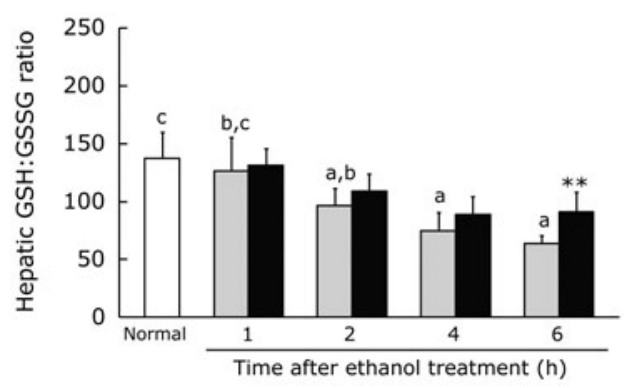

(B)

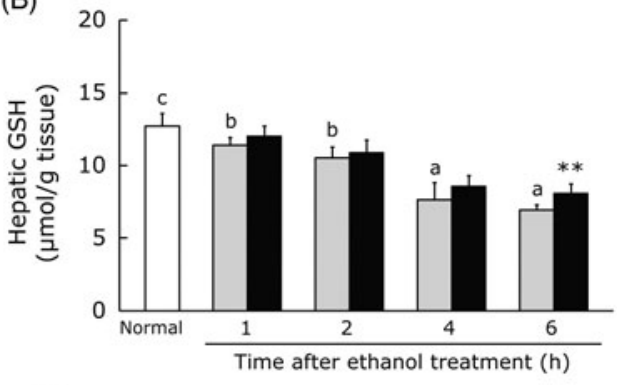

(D)

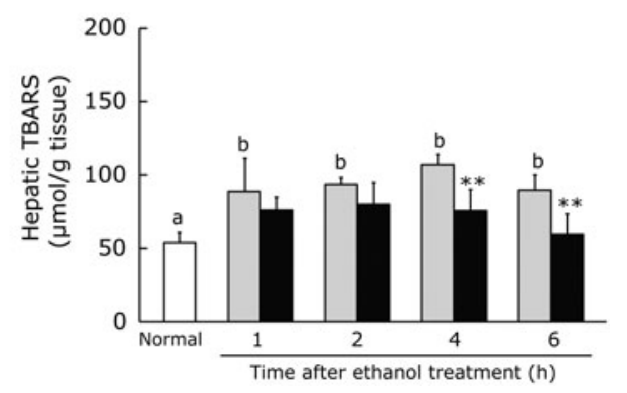

Fig. 4. Effects of oral administration of hot water extract of Curcuma longa (WEC) on hepatic antioxidant activities and hepatic lipid peroxide content after a single

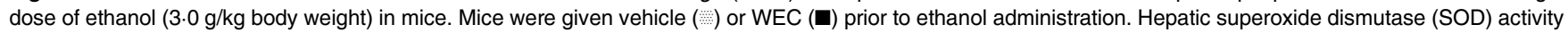
(A), glutathione (GSH) level (B), glutathione:oxidised glutathione (GSH:GSSG) ratio (C) and thiobarbituric acid-reactive substances (TBARS) (D) were measured immediately before $(\square)$ and after the ethanol administration. Values are means for $n 6$ (control and WEC groups) or $n 12$ (normal group), with standard deviations represented by vertical bars. ${ }^{a, b, c}$ For bars accompanied by letters, mean values with unlike letters were significantly different $(P<0.05$; one-way ANOVA, post hoc Tukey-Kramer test). Mean value was significantly different from that of the control group: ${ }^{*} P<0.05,{ }^{* *} P<0.01$ (unpaired Student's $t$ test).

of plasma AST and ALT levels. In addition to the increase of plasma AST and ALT, mice given ethanol $(3 \cdot 0 \mathrm{~g} / \mathrm{kg})$ displayed a decrease of hepatic SOD activity, hepatic GSH level, and hepatic GSH:GSSG ratio, as well as an increase in hepatic TBARS level, hepatic TNF- $\alpha$ protein production and hepatic IL-6 mRNA expression. These changes due to administration of ethanol were significantly suppressed by pretreatment with WEC. In addition, we demonstrated that pretreatment with bisacurone significantly suppressed the elevation of plasma ALT after ethanol administration. Our findings suggest that WEC protects against ethanol-induced liver injury by maintaining hepatic antioxidant capacity, inhibiting hepatic lipid peroxidation, and inhibiting inflammatory cytokine production, with these effects being partly mediated through the actions of bisacurone.

The serum levels of AST and ALT reflect hepatocyte damage. AST is found in high concentrations in the liver, heart, skeletal muscle and kidneys, whereas ALT is more abundant in the liver than in other tissues. Therefore, ALT is thought to be more sensitive for detecting hepatocellular injury and is more specific to the liver than AST. However, it has been reported that AST increases preferentially in patients with alcoholic liver injury and there is only mild elevation of ALT ${ }^{(44)}$. In contrast, we found that both plasma AST and ALT were similarly elevated in the control group after mice were given a single dose of ethanol (Fig. 1(A) and (B)). Although it is uncertain which is a more reliable marker of ethanol-induced liver injury, elevation of both enzymes was significantly suppressed by WEC.

Ethanol-induced oxidative stress is known to play an important role in liver injury. Metabolism of ethanol via cytochrome P450 2E1 (CYP2E1) is an alternative pathway involving production of superoxide anion radicals $\left(\mathrm{O}_{2}^{*-}\right)^{(7)}$. SOD can convert $\mathrm{O}_{2}^{--}$into $\mathrm{H}_{2} \mathrm{O}_{2}$, but its activity is inhibited by an excess of $\mathrm{O}_{2}^{--}$and $\mathrm{H}_{2} \mathrm{O}_{2}$, suggesting that the level of SOD activity is an indicator of the severity of oxidative stress $^{(3,7,45)}$. In fact, it has been reported that infusion of ethanol increases hepatic $\mathrm{O}_{2}^{--}$production in rats ${ }^{(46)}$, while production of ROS by metabolism of ethanol leads to inactivation of $\mathrm{SOD}^{(47)}$. In accordance with these observations, we found that acute ethanol administration led to marked reduction of hepatic SOD activity in the control group. Aqueous extracts of turmeric have been reported to suppress in vitro $\mathrm{O}_{2}^{--}$production at $2 \mathrm{~h}$ after exposure to pyrogallol, an $\mathrm{O}_{2}^{--}$generator ${ }^{(48)}$, and also inhibit the decrease of myocardial SOD activity induced by ischaemia-reperfusion in rats ${ }^{(49,50)}$. Similar to these observations, we demonstrated that WEC inhibited the decrease of SOD activity after ethanol administration, probably by suppressing $\mathrm{O}_{2}^{\cdot-}$ production. Alleviation of oxidative stress by WEC was confirmed because it inhibited the decrease of both hepatic tissue GSH and the GSH:GSSG ratio in mice treated with ethanol (Fig. 4(B) and (C)) and also significantly reduced the elevation of hepatic TBARS induced by ethanol (Fig. 4(D)). These results suggest that WEC maintains sufficient hepatic antioxidant activity to inhibit an increase of lipid peroxidation and ameliorate liver injury after acute ethanol administration.

Both clinical and animal studies have revealed that inflammatory cytokines such as TNF- $\alpha$ and IL- 6 are key mediators of ethanol-induced liver injury ${ }^{(10,1)}$, with apoptosis being induced by TNF- $\alpha$ and progression of hepatic inflammation being caused by both TNF- $\alpha$ and IL- 6 . We observed that 


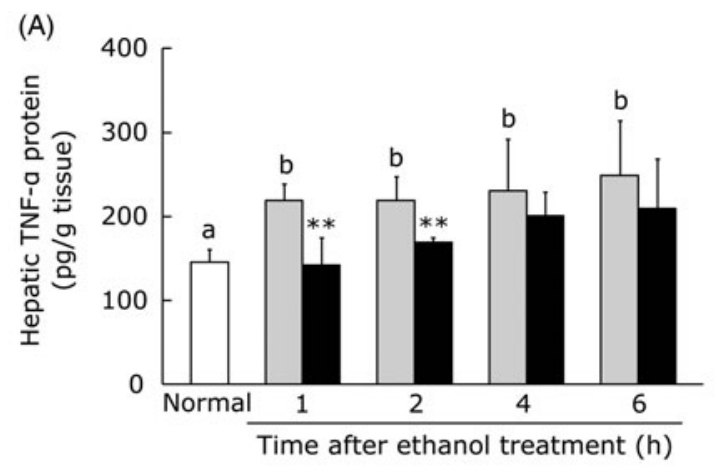

(B)

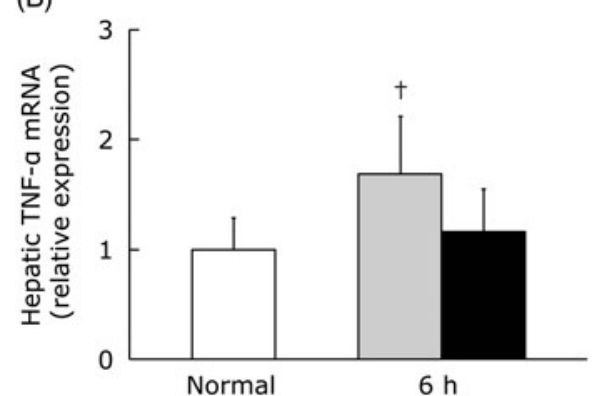

(C)

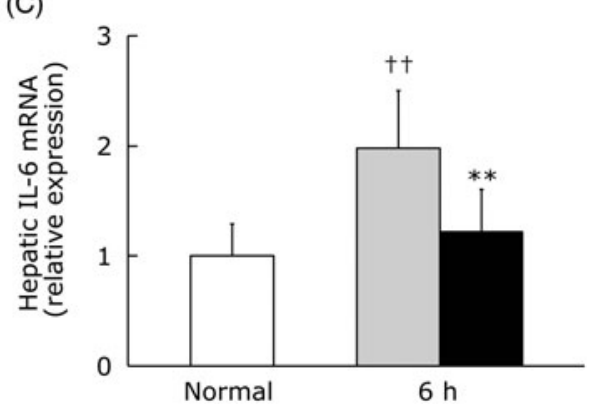

Fig. 5. Effect of oral administration of hot water extract of Curcuma longa (WEC) on hepatic inflammatory cytokines after a single dose of ethanol (3.0 g/kg body weight) in mice. Mice were given vehicle (-) or WEC (ם) prior to ethanol administration. Hepatic TNF- $\alpha$ protein content (A), TNF- $\alpha$ mRNA level (B) and IL-6 mRNA level $(C)$ were measured immediately before $(\square)$ and after the ethanol administration. The mRNA levels were quantified by using $\beta$-actin as the internal standard. Protein values are means for $n 6$ (control and WEC groups) or $n 12$ (normal group), with standard deviations represented by vertical bars. mRNA values are means for $n 6$ (normal, control and WEC groups), with standard deviations represented by vertical bars. ${ }^{a, b}$ For bars accompanied by letters, mean values with unlike letters were significantly different $\left(P<0.05\right.$; one-way ANOVA, post hoc Tukey-Kramer test). ${ }^{\star \star}$ Mean value was significantly different from that of the control group $(P<0.01$; unpaired Student's $t$ test). Mean value was significantly different from that of the normal group: $† P<0.05, \dagger \dagger P<0.01$ (unpaired Student's $t$ test).

WEC inhibited elevation of the hepatic TNF- $\alpha$ protein level in the early period after ethanol administration (Fig. 5(A)). Antioxidant treatment was reported to suppress induction of TNF- $\alpha$ protein in the liver at $1.5 \mathrm{~h}$ after acute ethanol administration in mice, possibly by suppressing ROS production $^{(37,51)}$. In the present study, SOD activity remained high in the WEC group at 1 to $2 \mathrm{~h}$ after ethanol administration (Fig. 4(A)), suggesting that preservation of hepatic antioxidant activity by WEC may suppress induction of $\mathrm{TNF}-\alpha$ protein production in the liver after ethanol administration. Activation of TNF- $\alpha$ signalling induces both TNF- $\alpha$ and IL-6 gene expression via the NF- $\mathrm{KB}$ signalling pathway ${ }^{(52)}$. Therefore, the increase of hepatic TNF- $\alpha$ and IL- 6 mRNA expression at $6 \mathrm{~h}$ after ethanol administration that we detected in the present study was presumably related to elevation of hepatic TNF- $\alpha$ protein production. Accordingly, suppression of the increase in hepatic TNF- $\alpha$ protein after ethanol administration by pretreatment with WEC (Fig. 5(A)) could be associated with less induction of TNF- $\alpha$ and IL- 6 mRNA in ethanol-treated mice (Fig. 5(B) and (C)). However, the possibility that expression of these mRNAs was reduced by inhibition of the NF- $\mathrm{KB}$ signalling pathway cannot be excluded.

Our previous study provided evidence that the antiinflammatory activity of WEC, which inhibits the $N F-\kappa B$ signalling pathway, is partly due to a component called bisacurone ${ }^{(22)}$. Bisacurone has been found to suppress elevation of ROS, activation of $\mathrm{NF}-\kappa \mathrm{B}$ and expression of vascular cell adhesion molecules ${ }^{(17)}$. The present study showed that pretreatment with WEC provided protection against ethanol-induced liver injury along with maintenance of antioxidant activity and suppression of the up-regulation of TNF- $\alpha$ and IL-6 mRNA expression. Pretreatment with bisacurone

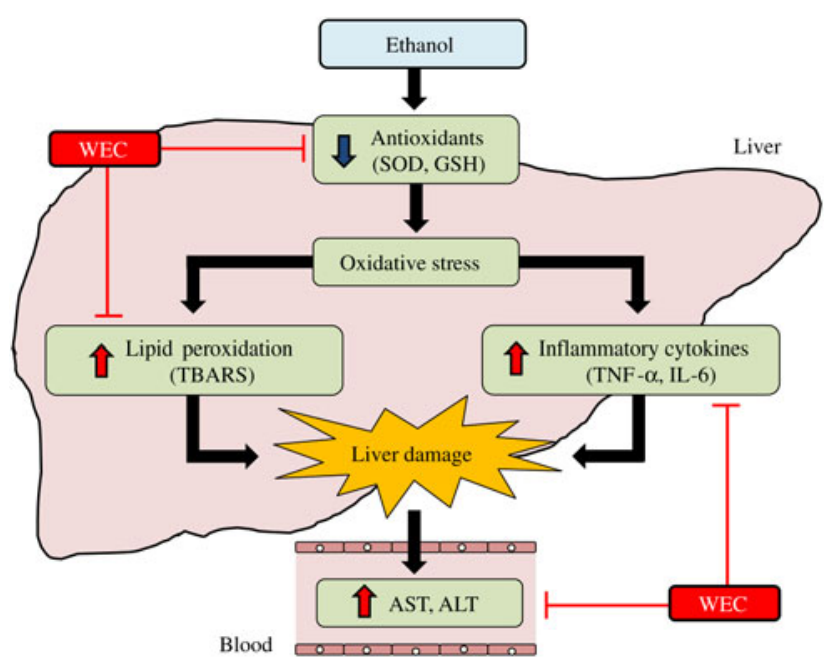

Fig. 6. Graphical summary of the effect of hot water extract of Curcuma longa (WEC) on acute ethanol-induced liver injury in mice. Pretreatment with WEC maintained hepatic antioxidant activity, inhibited lipid peroxidation and inhibited inflammatory cytokine production after acute ethanol administration, resulting in the prevention of acute ethanol-induced liver injury in mice. SOD, superoxide dismutase; GSH, glutathione; TBARS, thiobarbituric acid-reactive substances; AST, aspartate aminotransferase; ALT, alanine aminotransferase. 
also significantly suppressed the increase of ALT after ethanol administration (Fig. 2(B)), suggesting that the effects of WEC could be at least partly attributable to bisacurone and that it will be important to investigate the molecular mechanisms underlying the protective effect of bisacurone against ethanol-induced liver injury. In addition, since bisacurone pretreatment has a minor protective effect against ethanolinduced liver injury compared with the WEC effect, WEC components other than bisacurone may also be involved in the effect of WEC.

In conclusion, we demonstrated that pretreatment with WEC maintained hepatic antioxidant activity, inhibited lipid peroxidation and inhibited inflammatory cytokine production after acute ethanol administration, resulting in the prevention of acute ethanol-induced liver injury in mice (Fig. 6). These findings suggest that a hot water extract of turmeric has the potential to provide effective protection against ethanolinduced liver damage.

\section{Acknowledgements}

The authors thank Kotaro Onishi and Yoshihito Matsuda for preparing the hot water extract of turmeric.

This research received no specific grant from any funding agency, commercial or not-for-profit sectors.

The authors' contributions are as follows: R.U., T.H., K.M. and S.M. designed the study; R.U. and Y.H. conducted the animal study; Y.K. and T.H. made the bisacurone preparation; R.U. and Y.K. analysed the data; K.K., T.H., K.M. and S.M. participated in the interpretation of the results; R.U. wrote the manuscript; and S.M. had primary responsibility for the final content of the manuscript. All authors read and approved the final manuscript.

We declare that we have no conflicts of interest.

\section{References}

1. World Health Organization (2010) Global Strategy to Reduce the Harmful Use of Alcobol. Geneva, Switzerland: World Health Organization.

2. Shukla SD, Pruett SB, Szabo G, et al. (2013) Binge ethanol and liver: new molecular developments. Alcohol Clin Exp Res 37, 550-557.

3. Galicia-Moreno M \& Gutierrez-Reyes G (2014) The role of oxidative stress in the development of alcoholic liver disease. Rev Gastroenterol Mex 79, 135-144.

4. Gonzalez J, Munoz ME, Martin MI, et al. (1988) Influence of acute ethanol administration on hepatic glutathione metabolism in the rat. Alcohol 5, 103-106.

5. Ribiere C, Sinaceur J, Sabourault D, et al. (1985) Hepatic catalase and superoxide dismutases after acute ethanol administration in rats. Alcohol 2, 31-33.

6. Anundi I, Hogberg J \& Stead AH (1979) Glutathione depletion in isolated hepatocytes: its relation to lipid peroxidation and cell damage. Acta Pharmacol Toxicol (Copenh) 45, 45-51.

7. Sid B, Verrax J \& Calderon PB (2013) Role of oxidative stress in the pathogenesis of alcohol-induced liver disease. Free Radic Res 47, 894-904.

8. Takahashi M, Satake N, Yamashita H, et al. (2012) Ecklonia cava polyphenol protects the liver against ethanol-induced injury in rats. Biocbim Biophys Acta 1820, 978-988.
9. Wang AL, Wang JP, Wang H, et al. (2006) A dual effect of $\mathrm{N}$-acetylcysteine on acute ethanol-induced liver damage in mice. Hepatol Res 34, 199-206.

10. Yin M, Wheeler MD, Kono H, et al. (1999) Essential role of tumor necrosis factor $\alpha$ in alcohol-induced liver injury in mice. Gastroenterology 117, 942-952.

11. An L, Wang X \& Cederbaum AI (2012) Cytokines in alcoholic liver disease. Arch Toxicol 86, 1337-1348.

12. Guicciardi ME, Deussing J, Miyoshi H, et al. (2000) Cathepsin B contributes to TNF- $\alpha$-mediated hepatocyte apoptosis by promoting mitochondrial release of cytochrome c. J Clin Invest 106, 1127-1137.

13. Yan SL \& Yin MC (2007) Protective and alleviative effects from 4 cysteine-containing compounds on ethanol-induced acute liver injury through suppression of oxidation and inflammation. $J$ Food Sci 72, S511-S515.

14. El-Bahr SM (2015) Effect of curcumin on hepatic antioxidant enzymes activities and gene expressions in rats intoxicated with aflatoxin B1. Phytother Res: PTR 29, 134-140.

15. Gupta SC, Sung B, Kim JH, et al. (2013) Multitargeting by turmeric, the golden spice: from kitchen to clinic. Mol Nutr Food Res 57, 1510-1528.

16. Kim M, Chun S \& Choi J (2013) Effects of turmeric (Curcuma longa L.) on antioxidative systems and oxidative damage in rats fed a high fat and cholesterol diet. J Korean Soc Food Sci Nutr 42, 570-576.

17. Sun DI, Nizamutdinova IT, Kim YM, et al. (2008) Bisacurone inhibits adhesion of inflammatory monocytes or cancer cells to endothelial cells through down-regulation of VCAM-1 expression. Int Immunopharmacol 8, 1272-1281.

18. Mehra KS, Mikuni I, Gupta U, et al. (1984) Curcuma longa (Linn) drops in corneal wound healing. Tokai J Exp Clin Med 9, 27-31.

19. Yu ZF, Kong LD \& Chen Y (2002) Antidepressant activity of aqueous extracts of Curcuma longa in mice. J Ethnopharmacol 83, $161-165$.

20. Li Y, Shi X, Zhang J, et al. (2014) Hepatic protection and anticancer activity of Curcuma: a potential chemopreventive strategy against hepatocellular carcinoma. Int J Oncol 44, 505-513.

21. Cheng JJ, Yang NB, Wu L, et al. (2014) Effects of zedoary turmeric oil on P450 activities in rats with liver cirrhosis induced by thioacetamide. Int J Clin Exp Pathol 7, 7854-7862.

22. Kawasaki K, Muroyama K, Yamamoto N, et al. (2015) A hot water extract of Curcuma longa inhibits adhesion molecule protein expression and monocyte adhesion to TNF- $\alpha$-stimulated human endothelial cells. Biosci Biotechnol Biochem 79, 1654-1659.

23. Balaji S \& Chempakam B (2010) Toxicity prediction of compounds from turmeric (Curcuma longa L). Food Chem Toxicol 48, 2951-2959.

24. The Ministry of Health Labour and Welfare (2014) Japanese Pharmacopoeia 16th Edition Supplement II. Tokyo: Pharmaceutical and Medical Device Regulatory Science Society of Japan.

25. Reeves PG, Nielsen FH \& Fahey GC Jr (1993) AIN-93 purified diets for laboratory rodents: final report of the American Institute of Nutrition ad hoc writing committee on the reformulation of the AIN-76A rodent diet. J Nutr 123, 1939-1951.

26. Karmen A, Wróblewski F \& LaDue JS (1955) Transaminase activity in human blood. J Clin Invest 34, 126-133.

27. Inafuku M, Nugara RN, Kamiyama Y, et al. (2013) Cirsium brevicaule A. GRAY leaf inhibits adipogenesis in 3T3-L1 cells and C57BL/6 mice. Lipids Health Dis 12, 124.

28. Fischer AH, Jacobson KA, Rose J, et al. (2008) Hematoxylin and eosin staining of tissue and cell sections. CSH Protocs 2008, pdb. prot4986.

29. Zhou Z, Sun X \& James Kang Y (2002) Metallothionein protection against alcoholic liver injury through inhibition of oxidative stress. Exp Biol Med (Maywood) 227, 214-222.

30. Peskin AV \& Winterbourn CC (2000) A microtiter plate assay for superoxide dismutase using a water-soluble tetrazolium salt (WST-1). Clin Chim Acta 293, 157-166.

31. Zhu JH \& Lei XG (2011) Lipopolysaccharide-induced hepatic oxidative injury is not potentiated by knockout of GPX1 and SOD1 in mice. Biochem Biophys Res Commun 404, 559-563. 
32. Rahman I, Kode A \& Biswas SK (2006) Assay for quantitative determination of glutathione and glutathione disulfide levels using enzymatic recycling method. Nat Protoc 1, 3159-3165.

33. Morito N, Yoh K, Itoh K, et al. (2003) Nrf2 regulates the sensitivity of death receptor signals by affecting intracellular glutathione levels. Oncogene 22, 9275-9281.

34. Ohkawa H, Ohishi N \& Yagi K (1979) Assay for lipid peroxides in animal tissues by thiobarbituric acid reaction. Anal Biochem 95, 351-358.

35. Kang X, Zhong W, Liu J, et al. (2009) Zinc supplementation reverses alcohol-induced steatosis in mice through reactivating hepatocyte nuclear factor- $4 \alpha$ and peroxisome proliferator-activated receptor- $\alpha$. Hepatology 50, 1241-1250.

36. Engvall E \& Perlmann P (1971) Enzyme-linked immunosorbent assay (ELISA). Quantitative assay of immunoglobulin G. Immunochemistry 8, 871-874.

37. Zhou Z, Wang L, Song Z, et al. (2003) A critical involvement of oxidative stress in acute alcohol-induced hepatic TNF- $\alpha$ production. Am J Pathol 163, 1137-1146.

38. Kan WH, Hsu JT, Schwacha MG, et al. (2008) Selective inhibition of iNOS attenuates trauma-hemorrhage/resuscitation-induced hepatic injury. J Appl Physiol (1985) 105, 1076-1082.

39. Pfaffl MW (2001) A new mathematical model for relative quantification in real-time RT-PCR. Nucleic Acids Res 29, e45.

40. Livak KJ \& Schmittgen TD (2001) Analysis of relative gene expression data using real-time quantitative PCR and the $2^{-\Delta \Lambda \mathrm{CT}}$ method. Methods 25, 402-408.

41. Takahashi M, Kitamoto D, Imura T, et al. (2008) Characterization and bioavailability of liposomes containing a ukon extract. Biosci Biotechnol Biochem 72, 1199-1205.

42. Wang J, Zhang Y, Zhang Y, et al. (2012) Protective effect of Lysimachia christinae against acute alcohol-induced liver injury in mice. Biosci Trends 6, 89-97.
43. Mishra A, Paul S \& Swarnakar S (2011) Downregulation of matrix metalloproteinase- 9 by melatonin during prevention of alcoholinduced liver injury in mice. Biochimie 93, 854-866.

44. Sorbi D, Boynton J \& Lindor KD (1999) The ratio of aspartate aminotransferase to alanine aminotransferase: potential value in differentiating nonalcoholic steatohepatitis from alcoholic liver disease. Am J Gastroenterol 94, 1018-1022.

45. Salo DC, Pacifici RE, Lin SW, et al. (1990) Superoxide dismutase undergoes proteolysis and fragmentation following oxidative modification and inactivation. J Biol Chem 265, 11919-11927.

46. Bautista AP \& Spitzer JJ (1992) Acute ethanol intoxication stimulates superoxide anion production by in situ perfused rat liver. Hepatology 15, 892-898.

47. Santiard D, Ribiére C, Nordmann R, et al. (1995) Inactivation of $\mathrm{Cu}, \mathrm{Zn}$-superoxide dismutase by free radicals derived from ethanol metabolism: a $\gamma$ radiolysis study. Free Radic Biol Med 19, 121-127.

48. Koo BS, Lee WC, Chung KH, et al. (2004) A water extract of Curcuma longa L. (Zingiberaceae) rescues PC12 cell death caused by pyrogallol or hypoxia/reoxygenation and attenuates hydrogen peroxide induced injury in PC12 cells. Life Sci 75, 2363-2375.

49. Gu W, Weihrauch D, Tanaka K, et al. (2003) Reactive oxygen species are critical mediators of coronary collateral development in a canine model. Am J Physiol Heart Circ Physiol 285, H1582-H1589.

50. Mohanty I, Singh Arya D, Dinda A, et al. (2004) Protective effects of Curcuma longa on ischemia-reperfusion induced myocardial injuries and their mechanisms. Life Sci 75, 1701-1711.

51. Zhao J, Chen H \& Li Y (2008) Protective effect of bicyclol on acute alcohol-induced liver injury in mice. Eur J Pharmacol 586, 322-331.

52. Verma IM, Stevenson JK, Schwarz EM, et al. (1995) Rel/NF-кB/ IКB family: intimate tales of association and dissociation. Genes Dev 9, 2723-2735. 